\title{
Nonverbal Communication as a Means of Social Integration: The Development of Nonverbal Communication in Primary Schoolers with Intellectual Disabilities
}

\author{
Oksana V. Zashchirinskaia*
}

\author{
Department of Pedagogics and Pedagogical Psychology, Saint Petersburg State University, Saint \\ Petersburg, Russian Federation
}

\begin{abstract}
Objective: The study of nonverbal communication in primary schoolers with intellectual disabilities is an urgent topic for medical psychology.

Background: The purpose of this paper is to study nonverbal communication as a means of social integration.

Method: The methodological basis of this study is represented by various theoretic methods of scientific cognition. Methods of synthesis and analysis, system analysis of data and analysis of literary sources were used. In the context of the study, papers of foreign authors on the topic of nonverbal communication were considered.

Results: The study of the nonverbal communication development in primary school-aged children will allow for more successful socialisation of children with mild mental retardation, which in turn partially compensates for the intellectual impairment, and will also reduce the risks of social isolation.

Conclusion: This study is of practical value for psychologists and educators who work with children with a certain level of intellectual disability.
\end{abstract}

Keywords: Schoolchildren, communication, intellectual disability, psychological influence, socialisation.

\section{INTRODUCTION}

Social integration and subsequent socialisation of the child set a special task for specialists who implement programmes of psychological influence when working with children with mild intellectual disabilities. Nonverbal communication is considered as a compensatory opportunity for socialisation [1]. This problem is given attention by representatives of different psychological schools. Thus, the personally significant environment of the people with whom the subject interacts plays a significant role in the formation of his beliefs and values-based orientations, the boundaries of understanding acceptable behaviour, as well as directly motivating the subject.

In the study of the biological and social aspects of adaptation [2-4], a general view of the process under consideration can be seen: socialisation allows a person to accomplish individual development goals. At the same time, some specialists $[5,6]$ emphasise the importance of emotional and psychological support for children with learning difficulties. For sociologists, the socialisation can be viewed as a "social reproduction" of behaviour.

*Address correspondence to this author at the Saint Petersburg State University, Saint Petersburg, Russian Federation; Tel: +7812 36366 33; E-mail: zashchirinskaia5112@ubogazici.in
In general, when questions of the relationship between verbal and nonverbal communication are raised, it is important to understand its significance for the development of a child with intellectual disabilities. In various interdisciplinary studies, the development of communication is considered not only from the standpoint of humanism but also the issue of the phylogenesis of nonverbal communication is considered as a much earlier achievement of evolution. Such views are based on ideas about the biological role of emotions and their expression in primates, which were theoretically formulated by Charles Darwin, and then subjected to careful empirical verification by P. Ekman. In the studies, various classifications of basic expressions of emotions were identified, which made it possible to achieve significant results within the scope of the psychology of lying [7]. The primacy of nonverbal communication and its special significance for building a system of information exchange (the first acts as a model for the formation of the second) is also considered in the studies of Russian specialists [8].

These scientific facts are applied as a theoretical basis for modern experimental clinical psychology. Nonverbal communication in the presence of mental deficiency turns out to be an earlier method of communication and, as a result, is more closely related to the socialisation. Its mechanisms, in general, maybe less correlated with the level of development of consciousness and personality. Accordingly, purposeful work on the development of nonverbal communication 
will presumably allow for more successful socialisation of children with mild mental retardation, which in turn partially compensates for the intellectual impairment and reduces the risks of their social isolation.

\section{METHODOLOGY}

The research presented in this paper was carried out using theoretical methods of scientific cognition. The following methods of scientific cognition were used: the method of synthesis and analysis of data, system analysis of data. A theoretical analysis of literary sources on the topic of nonverbal communication was performed, the works of various authors who studied the topic of nonverbal communication as a means of social integration were considered.

A theoretical overview of scientific publications on the topic was used to consider social integration and nonverbal communication in children with intellectual disabilities. The features of nonverbal communication as a means of social integration were considered. The influence of nonverbal communication on the socialisation and adaptation of children with intellectual disabilities in society was analysed. It was found that in modern scientific publications, there is a relatively small number of clinical and psychological studies that address the development of nonverbal means of communication in children with mild mental retardation.

Using the synthesis method, which consists of combining related elements of an object or phenomenon into one whole, the main points of nonverbal communication were considered. In this study, the synthesis method was used to consider the features and positive aspects of the use of nonverbal communication as a means of social integration of children with intellectual disabilities. Using the method of analysis, the positive aspects of the introduction of nonverbal communication for primary schoolers were also analysed. This method is based on dividing the phenomenon into separate parts for a more detailed study. Using the method of analysis, it was revealed that nonverbal communication is one of the most effective ways of adaptation and socialisation for children with intellectual disabilities.

The method of systematic data analysis was also applied. Systematic data analysis was used for a detailed review of papers on the subject of nonverbal communication of primary schoolers with intellectual disabilities. Information about nonverbal communication for children with intellectual disabilities was analysed. Methods of socialisation of children with intellectual disabilities were considered.

A theoretical analysis of papers on the topic was carried out. Nonverbal communication as a means of social integration for children with intellectual disabilities has been insufficiently studied. However, some researchers in the field of pedagogy and psychology have considered this issue. The papers concerning social integration and nonverbal communication were reviewed. In the first paper reviewed, researchers investigate the relationship between gestures and various attention processes in adolescents with an autism spectrum disorder. The authors note that the analysis carried out in the paper indicated a significant correlation between gestures and warning, orientation, and attention. The results obtained in the paper can be applied in practice both to the development of gestures and to studies of attention in adolescents with an autism spectrum disorder. In the second paper reviewed, the authors conducted a study on the issue of social integration of children with intellectual disabilities. The study took place among parents of children with and without intellectual disabilities. The results showed that parents of children with intellectual disabilities are more likely to respond to the child's emotions. Correlation and regression analysis emphasises specific links between certain maternal and paternal reactions and conversations, on the one hand, and the characteristics of children, their social integration or behavioural problems, on the other.

\section{RESULTS}

\section{Nonverbal Communication as A Means of Social Integration}

Since the socialisation is considered as a process of personality development based on interaction with other people, we can say that it is directly related to communication development. Consideration of social integration from the standpoint of the establishment of the necessary conditions for the disclosure of communicative potential in the context of studying children with mild mental retardation in the primary school system is of particular importance for the study. If we rely on the basic provisions of humanistic psychology when studying their nonverbal communication, then the process of social integration itself will be presented as an opportunity to create the prerequisites for self-actualisation of the individual. This consideration of socialisation makes it possible to 
discover and apply effective means of psychological influence as a derivative of the compensation mechanism in children with mild mental retardation. In the process of personal development, the child not only strives to meet urgent needs but also to a variety of interactions with society. These views are widely considered not only within the framework of humanistic psychology. Ideas about how a child's interaction with the external social environment forms his personal identity has become central. In general, Russian psychologists have scientifically substantiated ideas about the relationship between the socialisation and the of activities at different stages of development, and also developed questions about the role of the human personality in the process of socialisation $[9,10]$. A.N. Leontiev, within the framework of his theory of activity, points to the social source of the formation of a complex structure of motives, which are also manifested in communication.

Various representatives of humanistic psychology emphasised the fact that through self-actualisation, a person develops creative abilities. This, in turn, not only contributes to success in social life but also becomes a psychological determinant of an individual's adaptation to different living conditions and helps to prevent possible difficulties in communication and the problem of deviant conduct [11].

The parameters of social integration in children with intellectual disabilities are labile and changeable. This is due to the state of the psyche from the organic damage to the central nervous system, as well as negative environmental factors, among which situational reasons are more likely to appear. In the context of studying the social integration of children with mild mental retardation, it is worth noting that, in aggregate, these parameters, with the relative stability of manifestations, can be considered as completely reliable criteria for social integration or as predictive factors. In this case, it is important to define them not only as personal qualities but as psychological and psychophysiological characteristics of communication and behaviour, largely taking into account the functional state of the central nervous system [12].

The process and the effectiveness of social integration have become the central forming link since they directly affect the personality development in the socio-cultural environment, and, consequently, the development of communication skills, methods of interaction, as well as the prerequisites for selfrealisation of children. It should be noted that the Law of the Russian Federation "On Education" focuses on the development of a child's social competence, the ability to navigate and appropriately respond in various situations of interaction with society and in communication. For children with severe intellectual disabilities, it is especially difficult to communicate successfully [13].

The successful adaptation of a child in society has an impact on all structural components of his life. Communicative development, in turn, directly affects the socialisation of the individual. The study of this process is significant for improving the quality of social integration of children with intellectual disabilities. Qualitative indicators of social integration also depend on various institutions of socialisation: family, school, society, that is, all those social communities in which the child learns to be involved in social relations, acquire standards of social behaviour, assimilates group norms and is formed as a subject of social interaction [14].

When assessing the quality of socialisation, researchers pay attention not only to the actual development of a child but also to the quality of his joint activities with those who directly contribute to socialisation. Interaction with parents, teachers and peers helps to assimilate all the experience necessary for the child's further social development. Various authors emphasise the importance of a dynamic assessment of the quality of the social situation of a child's development as a member of society.

Communication is the leading determinant of the personal adaptation of children with mild mental retardation since socialisation includes the process and conditions of the interaction of a person with the surroundings. Therefore, attention is paid to the characteristics of a child's personal adaptation both in micro- and macro-groups. At the same time, social communities will have different meanings at different stages of development, and as a means of influence, targeted programmes of influence on the communication of children both through micro- and macro social environments will be the most effective.

Thus, we can say that communication and the process of social adaptation are inextricably linked and determine the result of socialisation of children with intellectual disabilities. Nonverbal communication is an integral part of the communication process. It becomes a means of compensation in the presence of mental retardation in a child since it is phylogenetically earlier than verbal communication [15]. 
The problem of communication of children with intellectual disabilities is, according to modern researchers [16], insufficiently studied. It is often viewed precisely from the perspective of pedagogy. However, in order to understand the problem at hand and search for the content of effective educational programmes, it is important to consider communication from the standpoint of knowledge in the field of psychology, which will allow not only to identify significant compensatory features of the communication of children with mild mental retardation but also to analyse the complex of reasons underlying intellectual disabilities and affecting the dynamics of the child's mental development, which interferes with normal communication with adults and impede the socialisation process. A special task is to consider the question of how to compensate for underdevelopment and what intact spheres of the psyche can contribute to the activation of compensatory mechanisms in the process of nonverbal communication.

Within the framework of the study, it is necessary to dwell on the present features of intellectual disabilities. In children with mild mental retardation, difficulties in nonverbal means of communication are associated, first of all, with motor disorders, lack of emotional development, inability to express their own emotions and understand facial expressions of other people against the background of a decreased ability of such children to use communicative signs $[17,18]$ correctly. Insufficient development of emotional control in children with mild mental retardation in some cases can negatively affect the development of nonverbal communication due to difficulties in coping behaviour $[19,20]$. However, the question of the actual existence of significant difficulties in the expression and understanding of emotions by children with mild mental retardation remains very controversial, since there are comparative data indicating that these children do not experience limitations leading to the impossibility of their gradual socialisation. However, the totality of experimental data suggests that it is difficult for children with mild mental retardation to control and express their emotions in the process of communication, and at the level of cognitive processes, the lack of understanding of the facial expressions and gestures of the interlocutors is revealed. All researchers highlight the connection between social adaptation and communication skills, which becomes the theoretical basis for the development of programmes for the development of nonverbal communication in children with intellectual disabilities.
Among the papers on the subject, there is a relatively small number of clinical and psychological studies that touch upon the development of nonverbal means of communication in children with mild mental retardation. However, the following techniques and forms of influence exist and are actively used: verbal instructions, video training, which can help with the identification and expression of emotions, and also facilitate control over the behaviour of a child with intellectual disability.

These possibilities of psychological influence are also separate exercises created within the framework of a behavioural approach and aimed at the assimilation of specific communication techniques by children. To increase the efficiency of their assimilation, various stimulating material can be used, that is, the work is carried out based on both the direct behaviour of children and in the context of observing their communication using video recordings. In the process of helping children, both direct reinforcement [21] and various instructions and commands are used to regularly correct their behaviour. In addition, the intervention can be carried out in a complex with a drug effect, which ultimately increases its potential effectiveness [22].

The main feature of various programmes of psychological influence is their focus on specific communication difficulties in children when a specialist establishes the target of influence and consistent clinical and psychological work is carried out with it. With this approach, the development of the communication component dominates, which is considered as a potential resource for social adaptation. Indeed, the conscious control of mental processes allows one to overcome the existing limitations in the functioning of the psyche of a child with mild mental retardation. However, a need remains to take into account the individual characteristics of such children, since the variety of violations in the volitional sphere can significantly reduce the effectiveness of psychological influence using standardised programmes with universal methods for the development of nonverbal communication.

Thus, communication, communicative processes are an important determinant of the socialisation process, without which it is impossible for a child to assimilate the personal social experience. At the same time, the development of the nonverbal sphere becomes the most important compensatory opportunity 
in the communication of children with adults and peers. Socialisation slows down significantly if the conditions for a constant influence on the mental state and communication skills are not established, taking into account the age-related patterns of dysontogenesis in the presence of persistent and irreversible intellectual disabilities. The totality of scientific ideas on the peculiarities of communication against the background of intellectual disabilities is the basis for the development of applied aspects of their interaction with people around them, which in general, taking into account mental dysontogenesis, will positively affect the communicative and personal development and socialisation of children with mild mental retardation.

\section{The Development of Nonverbal Communication in Children with Intellectual Disabilities by Means of Psychological Influence}

When considering the methodological foundations of psychological influence on the development of nonverbal communication, the modern paradigms of clinical and psychological research in medical psychology are taken into account. This study has chosen the structural-dynamic approach, which allows us to consider the cognitive, emotional-personal and behavioural components of nonverbal communication in the process of adaptation to school. Attention is drawn not only to the relationship between the mental, biological and social aspects in the analysis of mental processes but primarily to the internal structure of communication, which is consistent with the objectives of the study. This methodological aspect is a further development and detailing of the biopsychosocial approach [23], adopted by clinical psychology from medicine. Within the framework of this approach, in the second half of the 20th century, there was a tendency for a radical revision of the primacy of the biological paradigm, the application of which often did not correspond to either experimental data or the current situation in the practical work of specialists [24]. In modern research, it is important to overcome the contradictions between the variety of different concepts of health and make the transition to a holistic consideration of a person and his health as a complex multi-level phenomenon.

The biopsychosocial approach was first established in 1980 as a working alternative to radical reductionism, which simplified the psychic solely to the level of neurophysiological processes in the brain. From that moment on, in medicine and related spheres, the phenomena of the mental and social gained their independence, which made it possible to consider them as independent factors available for scientific study and targeted influence.

In this clinical and psychological study, it is proposed to apply a structural-dynamic approach, which will allow paying sufficient attention to all areas of mental functioning of children, namely, cognitive, behavioural and emotional. A multicomponent consideration of nonverbal communication as a mental phenomenon will allow taking into account not only the external behaviour of children, as was customary among behaviourists, not only emotional states and motivation, which is used by supporters of psychodynamic and humanistic approaches, and not only various aspects of cognitive activity, but a complex of relationships and interconnections between these different, but combined with each other, components of the psychic sphere. Adhering to the structural-dynamic approach, followed by numerous psychologists, it is necessary to pay sufficient attention to the direct subjective experiences of children. Some researchers point to the fundamental importance of understanding, analysing and using subjective ideas about their own state and capabilities in children for the successful implementation of psychological influence on their nonverbal communication.

However, when using the corresponding research paradigm, it is also necessary, in addition to the possibilities, to be aware of its fundamental limitations. M.M. Reshetnikov in his study [24] indicates that in the modern biopsychosocial approach, attention is just beginning to be paid to social and psychological factors, and this attention may not be enough to form the most objective picture of developmental disorders in order to create and apply optimal programmes of psychological influence.

Thus, this study is focused on a multi-level analysis of human mental processes - the structural-dynamic approach, considers the psyche as a set of behavioural, emotional and cognitive spheres, which allows us to study and pay attention to both objective indicators of communicative development and its limiting factors, as well as subjective experiences that arise in children in connection with their states and communication skills. Moreover, paying enough attention to the mental factor of the development of primary schoolers, the problem of mild mental retardation from the standpoint of the development of nonverbal communication will be considered with 
respect to the latest achievements of medical psychology.

On the basis of the indicated research methodology, the specificity of intellectual disorders in children among other mental states was determined, the main approaches to the study of mental retardation as a special variant of underdevelopment were considered, which, as a medical phenomenon, has its own epidemiology, aetiology, pathogenesis, clinical picture and often a combination of concomitant diseases. As a clinical and psychological phenomenon, mental retardation is considered from the standpoint of the characteristics of the functioning of the cognitive, emotional, personal and behavioural spheres. For practising specialists, the presence of mental retardation in a child is, first of all, the problem of providing it with assistance in order to optimally compensate for persistent irreversible mental underdevelopment.

The prospect of further research makes it possible to develop ideas about intellectual disabilities in an interdisciplinary context, finding ways to solve the problems of developing effective programmes of psychological influence aimed at improving the quality of life of children with mild mental retardation. The emphasis on the study of the problems of the development of nonverbal communication in children opens up opportunities for the study of intact mental capabilities, which make it possible to partially compensate for the existing mental development disorders. Features of nonverbal communication are manifested in the early stages of a child's development. In order to prevent the negative influence of secondary factors of socialisation associated not with the disease, but with long-term limitations on the communication of children with the people it is advisable to begin to realise the child's potential in the development of cognitive, emotional, and behavioural spheres of communication.

It should be recognised that the approach of V.A. Labunskaya [25] is of heuristic and methodological significance for the development of an effective holistic programme of psychological influence in order to develop nonverbal communication in children with intellectual disabilities. The range of means offered by the author is primarily aimed at developing the control function, which allows children to master their own behaviour through training, to recognise their emotions and control them. In turn, the ability to understand and express their emotional states can contribute to the understanding of the emotional states of people with whom the child interacts.

A positive condition for the use of methods and techniques for providing assistance is the relative ease of their application since only one of the aspects of communication is affected, which allows the attention of a specialist to be focused on it. In addition, the centralisation of the influence preserves the purposefulness of communication development programmes. It is possible to consolidate the acquired skills in constant interaction with people in the framework of various activities, as well as in free time.

The main difficulties in assessing the effectiveness of such influences lie in their focus on one of the most important aspects of the development of nonverbal communication in children with intellectual disabilities behaviour control. At the same time, a purposeful influence on the regulation of mental processes can be carried out by rather limited methods of rendering assistance. These influences are made separately from other aspects. However, when defining the content of the programs, the effectiveness of a complex one, affecting all spheres of the human psyche, was repeatedly proved in comparison with isolated psychological influences aimed at separate goals. Only individual work on the social adaptation of the child is seen by the authors as ineffective and insufficient since, in addition to individual norms of behaviour and the ability to control his emotional state, a child with intellectual disabilities should be able to assimilate group norms and learn to understand the peers. It is not advisable to produce psychological influence without taking into account the individual developmental options of specific children without understanding their personal characteristics, which together will determine the context of helping the child and his family in the development of nonverbal communication. Taking into account the specifics of the development and implementation of programmes of psychological influence for children with intellectual disabilities makes it possible to achieve the effectiveness of psychological influence, compensate for their underdevelopment and overcome secondary difficulties in socialisation.

To test the considered predictive capabilities of the programme of psychological influence on the development of nonverbal communication skills, purposeful research work is required. The study material collected from several educational institutions will make it possible to test the practical results of 
providing assistance to primary school-aged children with intellectual disabilities.

\section{DISCUSSION}

Nonverbal communication as a means of social integration for children with intellectual disabilities is an insufficiently studied issue. However, some researchers in the field of pedagogy and psychology have considered this issue.

The authors of the paper "The relationship between gestures and nonverbal communication and attentional processing in high-functioning adolescents with autism spectrum disorder" investigate the relationship between gestures and various attention processes in adolescents with an autism spectrum disorder. They note that this issue has not been sufficiently studied. Previous research has highlighted the effect of focusing on the effectiveness of gestures without examining the effect of alerting and descending attention processes. The object of their study was to investigate the connections between attention processes and indicators of descriptive, conditional and emotional gestures, as well as other aspects of nonverbal communication in adolescents with an autism spectrum disorder. The attention network test and the colour trail test were used. These tests were used to measure attentional processes, while descriptive, standard and emotional gestures were assessed using the autism diagnostic observation schedule and diagnostic interview. The analysis carried out in this work showed a significant correlation between gestures with warning, orientation and attention. The corresponding structural equation model showed that attention processes affect gestures, but gestures do not affect attention processes. Emotional gestures are associated with the warning. Spatial visual search has been associated with facial expression and the integration of nonverbal communication with behaviour. There was no significant interaction between executive attention and gestures. The results obtained can be applied both to the development of gestures and to studies of attention in adolescents with an autism spectrum disorder [26]. This study and the results obtained are of practical value for medical psychology and pedagogy.

The paper "The unforeseen influence of parents' socialisation behaviours on the social adjustment of children with intellectual disabilities" explores the question of how parents of children with intellectual disabilities control emotions and how this behaviour affects the social integration of their children. The objectives of this study were: to determine the emotionrelated social behaviour used by the parents of children with disabilities, in comparison with the parents of typically developing children; to study the extent to which these reactions and conversations affect social competence and maladaptation of children. Parents who respond to emotions as supportive or nonsupportive of children's socialisation, their development and their conversations about emotions with children are also considered important in this matter. However, little is known about these reactions and conservatism in mothers or fathers of children with intellectual disabilities. The first study compared 54 mothers and 32 fathers of preschool children with and without intellectual disabilities. The results showed that parents of children with intellectual disabilities are more likely to respond to a child's emotions. The second study examined the relationship between parental responses and conversations and their children's profiles (identifiers, age, development). Correlation and regression analysis emphasise specific links between certain maternal and paternal reactions and conversations, on the one hand, and the characteristics of children, their social adaptation or behavioural problems, on the other [27]. This study also examines the issues of social adaptation of children with intellectual disabilities and is of interest to practising psychologists and teachers.

\section{CONCLUSIONS}

The present paper theoretically considers the issue that social integration is a special task for specialists who implement programmes of psychological influence when working with children with intellectual disabilities. The investigation of social adaptation from the perspective of the creation of the necessary conditions for disclosing the communicative potential in the context of studying children with mild mental retardation in the primary school system is of particular importance for the present study. Thus, this consideration of the socialisation process makes it possible to discover and apply effective means of psychological influence as a derivative of the compensation mechanism in children with mild mental retardation. It is important to note that in the aggregate, the parameters of social integration, with the relative stability of manifestations, can be considered as quite reliable criteria for social adaptation or as predictive factors.

It was determined that communicative processes are an important determinant of the socialisation 
process, without which it is impossible for a child to assimilate the personal social experience. The development of the nonverbal sphere is the most important compensatory opportunity in the communication of children with mild mental retardation with adults and peers. Socialisation slows down significantly if the conditions for a constant influence on the mental state and communication skills are not created for a child, taking into account the age-related patterns of dysontogenesis in the presence of persistent and irreversible intellectual disabilities.

It is not advisable to make psychological influence without taking into account the individual developmental options of specific children, without understanding their personal characteristics, which together will determine the context of helping the child and his family in the development of nonverbal communication. Taking into account the specifics of the development and implementation of psychological influence makes it possible to achieve the effectiveness of psychological influence when working with children, significant compensation for their underdevelopment and overcome secondary difficulties in socialisation, including such children in the social environment and forming stable skills of nonverbal communications.

Having analysed all of the above facts, it is important to note that further purposeful research is necessary to test the considered predictive capabilities of the psychological influence programme on the development of nonverbal communication skills. The materials and conclusions presented in this work, which were collected on the basis of several educational institutions, provide extended information about the features of communication in children with intellectual disabilities. This study is of practical importance for teachers, psychologists and doctors who work with children with intellectual disabilities, and will also make it possible to test the practical results of rendering assistance to primary school-aged children with intellectual disabilities.

\section{ACKNOWLEDGEMENTS}

None.

\section{REFERENCES}

Rybnikov VYu, Zashchirinskaia OV. Phenomenology of agerelated patterns of communication disorders in children and adolescents with mild mental retardation. Psychotherapy Bulletin 2013; 47: 71-85.
[2] Freud A. Psychology of I and defence mechanisms. Moscow: Pedagogika-Press, 1993.

[3] Freud S. Introduction to Psychoanalysis. St. Petersburg: Azbuka, 2009.416 p.

[4] Erickson EG. Identity: Youth and Crisis. Moscow: Progress, 2006.

[5] Fromm E. Man for Himself. Moscow: Astrel, 2012.

[6] Fromm E. To Have or to Be. Moscow: Astrel, 2007.

[7] Ekman P. Psychology of Emotions. St. Petersburg: Peter 2011.

[8] Mulatova NA, Ryabenchenko NN. Inclusive education of children with intellectual disabilities. International Journal of Experimental Education. Penza 2016; 4: 259-261.

[9] Ananiev BG. Man as a subject of knowledge. St. Petersburg: Peter 2001.

[10] Leontiev AN. Selected psychological works. Moscow: Pedagogika, 1983.

[11] Zmanovskaya EV. Deviantology. Moscow: Publishing Center "Akademiya" 2004

[12] Pecherskiy VG. Problems of socialisation of persons with mental underdevelopment. Bulletin of the Saratov State Technical University, 2005; 1(9): 169-179.

[13] Selivanova YuV, Shchetinina EB, Solovyova OV. Readiness of children with complex disabilities to school education. Bulletin of the Saratov University. New series. Acmeology of education. Developmental psychology 2017; 6(2): 186-190. https://doi.org/10.18500/2304-9790-2017-6-2-186-189

[14] Meshcheryakov BG, Zinchenko VP, Eds. Big psychological dictionary. St. Petersburg: Prime-Evroznak 2004.

[15] Mikhailovskaya EV. Communication among children of preschool and primary school education. Actual problems of modern science: a collection of articles of the International Scientific and Practical Conference: in 4 parts. Ed.-in-chief A. A. Sukiasyan. Ufa: Bashkir State University 2013; Part 1. p. 83-87.

[16] Zashchirinskaia OV. Communication disorder in children and adolescents with mild mental retardation: phenomenology, model, socialisation: PhD dissertation. St. Petersburg: St. Petersburg State University 2013.

[17] Hou L, Antion MD, Hu D, Spencer CM. Dynamic translational and proteasomal regulation of fragile $X$ mental retardation protein controls mGluR-dependent long-term depression. Neuron 2006; 51(4): 441-454 https://doi.org/10.1016/j.neuron.2006.07.005

[18] Hetzoni O, Oren B. Effects of intelligence level and place of residence on the ability of individuals with mental retardation to identify facial expressions. Research in developmental disabilities 2002; 23(6): 369-378. https://doi.org/10.1016/S0891-4222(02)00139-7

[19] Jahoda A, Pert C, Trower P. Frequent aggression and attribution of hostile intent in people with mild to moderate intellectual disabilities: an empirical investigation. American journal on mental retardation 2006; 111(2): 90-99. https://doi.org/10.1352/08958017(2006)111[90:FAAAOH]2.0.CO;2

[20] Matheson E, Jahoda A. Emotional understanding in aggressive and nonaggressive individuals with mild or moderate mental retardation. American Journal on Mental Retardation 2005; 110(1): 57-67. https://doi.org/10.1352/08958017(2005)110<57:EUIAAN>2.0.CO;2

[21] Millar DC, Light JC, Schlosser RW. The impact of augmentative and alternative communication intervention on the speech production of individuals with developmental disabilities. A research review. Journal of Speech, Language, and Hearing Research 2006; 49(2): 248-264. https://doi.org/10.1044/1092-4388(2006/021) 
[22] Winarni TI, Schneider A, Hagerman RJ. Early intervention combined with targeted treatment promotes cognitive and behavioral improvements in young children with fragile $X$ syndrome. Case reports in genetics. 2012. https://doi.org/10.1155/2012/280813

[23] Kholmogorova AB. Aggravation of the struggle of paradigms in the sciences of mental health: in search of a way out. Social and Clinical Psychiatry 2014; 24(4) 53-61.

[24] Reshetnikov MM. Mental health of the population in the light of modern trends. Neurological Bulletin, 2013. XLV (3) 71-77.

[25] Labunskaya VA. Applied research methodlogy nonverbal behavior. Saarbrücken: LAP Lambert Palmarium Academic Publishing 2014.
[26] Pudło M, Pisula E. The relationship between gestures and nonverbal communication and attentional processing in highfunctioning adolescents with autism spectrum disorder. Autism \& Developmental Language Impairments 2018; Vol. 3.

https://doi.org/10.1177/2396941518787139

[27] Jacobs E, Mazzone S, Simon P, Nader-Grosbois N. The unforeseen influence of parents' socialisation behaviours on the social adjustment of children with intellectual disabilities. Psychology 2019; 10 (9) 1275-1301. https://doi.org/10.4236/psych.2019.109083

Received on 30-10-2020

DOI: https://doi.org/10.6000/2292-2598.2020.08.04.3

(C) 2020 Oksana V. Zashchirinskaia; Licensee Lifescience Global.

This is an open access article licensed under the terms of the Creative Commons Attribution Non-Commercial License (http://creativecommons.org/licenses/by-nc/3.0/) which permits unrestricted, non-commercial use, distribution and reproduction in any medium, provided the work is properly cited. 